\title{
Laboreal
}

Volume $17 \mathrm{~N}^{\circ} 1$ | 2021

Trabalhar hoje: mudanças, permanências, estratégias, reinvenções

\section{Os debates entre a história e a psicologia: um recurso para compreender a atividade em situação de trabalho}

Los debates entre la historia y la psicología: un recurso para comprender la actividad en situación de trabajo

Les débats entre l'histoire et la psychologie, une ressource pour comprendre l'activité en situation de travail

The debates between history and psychology: a resource to understand the activity in work situation

\section{Régis Ouvrier-Bonnaz}

Tradutor. João Viana Jorge (joaojorg@gmail.com)

\section{(2) OpenEdition}

\section{Journals}

Edição electrónica

URL: https://journals.openedition.org/laboreal/17528

DOI: $10.4000 /$ laboreal. 17528

ISSN: 1646-5237

\section{Editora}

Universidade do Porto

Refêrencia eletrónica

Régis Ouvrier-Bonnaz, «Os debates entre a história e a psicologia: um recurso para compreender a atividade em situação de trabalho», Laboreal [Online], Volume 17 NN$^{\circ} 1$ | 2021, posto online no dia 18 junho 2021, consultado o 20 junho 2021. URL: http://journals.openedition.org/laboreal/17528 ; DOI: https://doi.org/10.4000/laboreal.17528

Este documento foi criado de forma automática no dia 20 junho 2021.

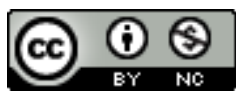

Laboreal está licenciado com uma Licença Creative Commons - Atribuição-NãoComercial 4.0 Internacional. 


\section{Os debates entre a história e a psicologia: um recurso para compreender a atividade em situação de trabalho}

Los debates entre la historia y la psicología: un recurso para comprender la actividad en situación de trabajo

Les débats entre l'histoire et la psychologie, une ressource pour comprendre

l'activité en situation de travail

The debates between history and psychology: a resource to understand the

activity in work situation

\section{Régis Ouvrier-Bonnaz}

Tradução : João Viana Jorge (joaojorg@gmail.com)

\section{NOTA DO EDITOR}

Manuscrito recebido em: 22/01/2021

Aceite após peritagem em: 18/02/2021

No texto Psychologie et histoire, vindo a lume em 1938 no tomo VIII da Encyclopédie Française [1], La vie mentale, coordenado pelo psicólogo Henri Wallon (1879-1962), o historiador Lucien Febvre (1878-1956) interroga-se sobre a colaboração possível entre os historiadores e os psicólogos: “como poderíamos nós historiadores ajudarmo-nos a interpretar as démarches de homens de outrora, graças a uma psicologia resultante da observação de homens do século XX? E como é que eles, psicólogos, poderiam encontrar, nos dados que a história lhes fornece (ou deveria fornecer) sobre a mentalidade dos homens de outrora, material com que pura e simplesmente enriqueceriam uma experiência adquirida no contacto com os seus contemporâneos?". 
2 A partir deste questionamento definiu a "próxima tarefa" dos historiadores e dos psicólogos interessados numa colaboração: "inventariar, primeiro em detalhe, e depois reconstruir, para a época estudada, o material mental de que dispunham os homens dessa época; por um possante esforço de erudição, mas também de imaginação, reconstituir o universo, todo o universo físico, intelectual, moral no meio do qual cada uma das gerações que a precederam se movimentaram". Febvre conclui assim o seu texto: "Aqui, trata-se de integrar uma psicologia histórica totalmente nova, a criar, na possante corrente de uma história que a encaminha como todas as coisas para o destino da humanidade - de uma humanidade que marcha sem saber para o que tende".

3 Nessa coerência, para Febvre, qualquer facto social tem uma natureza profundamente psicológica daí a ideia de que tudo o que é social é um produto de representações. Privilegiando o estudo das representações coletivas e das démarches que delas nos dão conta, Febvre faz do termo "mentalidades" o conceito unificador das suas pesquisas. Este conceito permite situar as ideias, as obras e os comportamentos dos homens e das mulheres - o que constitui a cultura em sentido lato - no contexto do seu aparecimento tendo em conta as condições sociais nas quais aparecem e ganham forma.

\section{História das mentalidades e história das sensibilidades, a emoção em questão}

4 Para Jacques Le Goff (1924-2014), um dos historiadores que se interessou pela obra de Febvre, a história das mentalidades é assim "ligada aos gestos, aos comportamentos, às atitudes - articulando-se assim com a psicologia, numa fronteira em que historiadores e psicólogos deverão um dia encontrar-se e colaborar" (1974, p. 89). A história das mentalidades estabelecendo a ligação entre os homens para os constituir coletivamente enquanto sujeitos da história favorece um trabalho pluridisciplinar: "A mentalidade de um indivíduo histórico, ainda que tenha sido um grande homem, é justamente o que ele tem de comum com outros homens do seu tempo" (idem, p. 78). o historiador de mentalidades, próximo do etnólogo, "deve também desdobrar-se em sociólogo" (idem, p. 28), já que "se cruza particularmente com o psicólogo social" (idem, p. 78). A história das mentalidades "situa-se no ponto da junção do individual com o coletivo, do tempo longo com o quotidiano, do inconsciente com o intencional, do estrutural com o conjuntural, do marginal com o geral. O nível da história das mentalidades é o do quotidiano e do automático, é o que escapa aos sujeitos individuais da história porque revelador do conteúdo impessoal do seu pensamento" (idem, p. 80). Designa "a coloração coletiva do psiquismo, o modo particular de pensar e de sentir dum povo, dum certo grupo de pessoas, etc." (idem, p. 82). Mentalidades e vida material constituem as bases de qualquer cultura. Para Febvre esta não pode ser bem compreendida senão se for relacionada com as condições possíveis, de onde a necessidade de a colocar no sistema de instrumentos e de significações das quais releva. Para bem levar a cabo esta tarefa, que considera "enorme" no seu texto de 1938, duas vias cardinais de estudo podem ser adotadas: a das técnicas e a da linguagem.

5 Nesse mesmo ano de 1938, Febvre interessa-se pelo que denomina "a via afetiva e suas manifestações" (1938/1943, p. 79) [²] para interrogar ligações que podem estabelecer-se entre sensibilidade e história. Para estabelecer essas ligações, mobiliza o conceito de emoção do qual especifica o enquadramento com referência a um texto de Wallon igualmente publicado na Encyclopédie Française (1938). "Pôde assistir-se nas civilizações 
em vias de desenvolvimento a esse longo drama do recalcamento mais ou menos lento da atividade emocional pela atividade intelectual; de início as únicas capazes de realizar entre os indivíduos a unidade de atitudes e de consciência de onde pôde nascer o comércio intelectual e a sua primeira técnica, entraram depois em conflito com os novos instrumentos de relação de que só elas tinham tornado possível a criação. E quanto mais as operações intelectuais se desenvolveram nos meios sociais em que todas as relações entre os homens se encontram cada vez melhor regulamentadas pelas instituições ou pelas técnicas - mais forte se tornou a tendência de considerar as emoções uma perturbação da atividade" (idem, p. 83-84). Para Febvre, o conceito de emoção, estabelecendo a ligação entre a história das mentalidades e da vida afetiva, permite "compreender um pouco melhor a atitude dos homens de outrora e talvez ainda definir um método de pesquisa" (idem, p. 84). 0 estudo das emoções como modo de acesso à vida afetiva permite retornar às primeiras determinações das sociedades e, portanto, da mulher e do homem em sociedade tomando em conta a construção dos laços entre o indivíduo e a sociedade [3].

6 Para Febvre ter em conta as emoções permite compreender a génese da atividade humana. Levado a discutir enquanto historiador o estatuto da emoção na psicologia de Wallon, especifica:

"as emoções, ao contrário do que se pensa quando se as confunde com simples automatismos de reação ao mundo exterior - têm um carácter particular do qual o homem que se ocupa da vida social dos seus congéneres não pode agora abstrair-se. As emoções são contagiosas. Implicam relações de homem a homem, relações coletivas. Nascem sem dúvida num fundo orgânico, específico para um dado indivíduo e frequentemente por ocasião de um acontecimento que toca apenas esse indivíduo ou que pelo menos o toca com uma particular gravidade ou violência. Mas elas exprimemse de certa maneira; se se quiser a sua expressão é o resultado de uma tal série de experiências, de vida comum, de reações semelhantes e simultâneas ao choque de situações idênticas e de contactos da mesma natureza; é ainda o fruto, se se preferir, duma tal fusão, duma tal redução recíproca de sensibilidades diversas - que, depressa adquirem o poder de provocar em todos os presentes, por uma espécie de contágio mimético, o complexo afetivo motor que corresponde ao acontecimento aparecido e sentido por um só. E assim, pouco a pouco, as emoções, associando diversos participantes alternadamente iniciadores e seguidores - acabam por constituir um sistema de incitação interindividual que se diversificou conforme as situações e as circunstâncias diversificando da mesma penada as reações e a sensibilidade de cada um. $\mathrm{E}$ isto, tanto mais que o acordo assim estabelecido, que a simultaneidade assim regulada das reações emotivas se mostrando suscetíveis de conferir ao grupo uma maior segurança ou uma maior potência $\theta$ - $a$ utilidade logo passou a justificar a constituição de um verdadeiro sistema de emoções. E elas tornaram-se como que uma instituição" (1941, p. 194-195) [4].

7 Febvre sublinhou que, para Wallon, as emoções, que constituem "uma nova fórmula de atividade", favorecem a articulação entre problemática sábia e problemática social. Wallon parte do postulado de que o trabalho e as suas formas de organização constituem a matriz da história social na qual se inscreve o desenvolvimento de homens e mulheres. No ponto de partida de qualquer educação está o trabalho, a "indústria humana" (Malrieu, 1981). A atividade é e faz história na medida em que nos permite compreender como mulheres e homens se desenvencilham para fazer o que 
têm a fazer no mundo. Logo uma questão se impõe: como é que o conceito de eatividade, entendido como um dos conceitos fundadores da psicologia, quando apreendida pelo lado da antropologia, pode penetrar o campo da história para desencadear e enriquecer o diálogo entre as duas disciplinas.

\section{O ofício sob o olhar cruzado da psicologia e da história, a atividade no trabalho}

80 exemplo apresentado para tentar responder a esta questão é retirado dum estudo, realizado a pedido do serviço de investigação dos correios franceses, respeitante ao ofício de chefe de equipa (Ouvrier-Bonnaz \& Prot, 2006). Um dos eixos da pesquisa, para estudar este ofício de chefe de equipa na distribuição, diz respeito à triagem geral do correio (TG) efetuada pelos carteiros para preparar os respetivos giros. Antes da mecanização da triagem do correio, introduzida nos centros de triagem a partir do início dos anos dois mil, a TG era, pois, efetuada pela equipa de carteiros sob a responsabilidade do chefe de equipa. $O$ objetivo desse trabalho coletivo com a duração de uma hora era o de selecionar um máximo de correio a fim de evitar aos utentes atrasos na distribuição, devendo o chefe de equipa proceder de modo a que o conjunto do correio fosse selecionado e remetido no mesmo dia. 0 que está em jogo é a gestão dos fluxos; fluxos do correio e fluxo do movimento das pessoas para evitar a "desordem" a fim de manter uma certa eficácia.

Por ocasião deste trabalho coletivo imposto, que obriga cada qual a colocar-se em consonância, o que primeiro chama a atenção do observador é a coordenação dos movimentos em espaços reduzidos, cada vez mais atulhados à medida que o trabalho avança (plásticos, papéis no chão, cartas amontoadas, ...). Neste quadro, em que as intervenções verbais são raras, a exatidão dos gestos efetuados, a rapidez e a eficácia das deslocações evitando que os corpos se toquem permitem regular a atividade coletiva e a individual. Se este movimento coordenado implica habilidades individuais e saberes coletivos, já o seu domínio não explica tudo, particularmente ao nível da coordenação do conjunto dos movimentos que garante a eficácia [5]. Ao nosso reparo respeitante a este movimento, uma espécie de ballet desenrolando-se à vista do observador, um diretor dum centro de triagem confessou que tinha renunciado a participar no trabalho coletivo por não encontrar nele o seu lugar e sentir dificuldades em se inserir no movimento geral, afirmando mesmo que tinha a impressão de incomodar, sublinhando assim a sua dificuldade em participar num género profissional que não era o seu e deste modo de partilhar o que os carteiros podiam viver e sentir nessa fase de trabalho coletivo.

Os deslocamentos, estabelecidos e postos em prática na triagem geral, dos quais cada qual guarda memória, inscrevem-se num cenário gestual de todos conhecido e em relação ao qual Febvre, no seu comentário sobre a emoção em Wallon, dá-nos as chaves para compreender a sua natureza e o seu papel. Obra coletiva, socialmente construída, que age por contágio até se tornar uma instituição que facilita o arranque matinal, permitindo a cada um ultrapassar, cada qual à sua maneira, mas em conjunto, os conflitos suscetíveis de serem gerados pelas diferenças entre o trabalho coletivo e o individual característicos dos ofícios da distribuição postal, num espaço reduzido, onde as tensões entre os diferentes atores são exacerbadas. 
11 De certo modo, neste palco interligando as pessoas na realização de uma tarefa comum, o que afeta cada um pode ser mediatizado corporal e socialmente pelo prazer ligado à perfeição do movimento e à eficácia que daí decorre. Quando a integração de todos nesse movimento é bem sucedida emerge mesmo uma certa beleza que legitima o recurso a referências artísticas em que a TG é comparada a uma coreografia [ 6 ]. 0 que está em jogo neste movimento tem uma história que se inscreve na história do ofício: o que os trabalhadores dele fizeram e a representação coletiva que eles fazem dele. Para compreender como cada pessoa, ao mesmo tempo, constrói e se emancipa da relação social com o trabalho, mas também dos invariantes subjetivos e operatórios de serem mobilizados em situação, é útil estudar "esta história" para ver o modo como cada um nela se inscreve e daí retira recursos para agir. Paul Bouffartigue et Jean Vandewattyne, num estudo recente realizado em cinco países europeus, intitulado Facteurs en Europe, realçam como a cisão em curso entre as atividades de triagem preparatória da jornada, por um lado e a da distribuição, por outro, desestabilizou a figura profissional dos carteiros. Daí que eles se interroguem: "Que papel desempenham os processos de liberalização das atividades postais, em paralelo com uma série de outras mutações técnico- organizacionais, no pôr em perigo este ofício?" (2020, p. 11).

12 Jacques Curie e Raymond Dupuy propõem-nos um possível caminho para esclarecer este questionamento. Estudando a evolução das conceções normativas da relação do homem com o trabalho e com a sua organização, mobilizam os trabalhos dos historiadores [ $\left.{ }^{7}\right]$ para demonstrar que estas conceções correspondem a "tentativas de conciliar duas solicitações contraditórias de unidade: a da organização, das suas estruturas e das suas componentes; a do trabalhador, das suas funções psicológicas e dos seus diferentes tempos e lugares de vida" (1996, p. 141). Para estes autores, se os psicólogos e os historiadores das formas materiais e sociais do trabalho por vezes se encontram, fazem-no de forma "fugidia como os viajantes que circulam nas passadeiras rolantes assíncronas de um lugar público" (idem, p. 141). Os lamentos destes autores não são de circunstância. Em meados dos anos sessenta a criação do Centre Interdisciplinaire d'Études Urbaines (CIEU), agrupando historiadores e psicólogos, mas também geógrafos, sociólogos e demógrafos na Universidade de Toulouse, tinha permitido a Curie estabelecer com Violette Hajjar (1987) as bases do "sistema de atividades", cuja contribuição para o desenvolvimento da psicologia não requer demonstração. Com efeito, permite estudar o entrelace dos determinismos sociais externos e o determinismo interno, pessoal, suscetível de facilitar a compreensão do modo como cada um se arranja para fazer face às suas obrigações nos seus diversos contextos de vida e como estes interagem.

\section{Para concluir sobre o lugar ocupado pelo conceito de emoção no diálogo entre disciplinas}

13 Philippe Malrieu, bem realçou, na prossecução dos trabalhos de Wallon, que, se a emoção é, no centro da vida psicológica, uma função de redistribuição e de reorientação das condutas que "permite a inflexão do comportamento em função das mudanças e sobretudo das reações de outrem (...), não é, todavia, absorvida no seio da conduta de adaptação (...). As numerosas falhas da emoção o comprovam e se há emoções de arranque comportando atitudes de preparação e de espera, também as há de descalabro" (1963, p. 128-129). Para Clot, que se inscreve na tradição dos trabalhos de 
Malrieu, "uma mesma e única sensação de estar à mercê, ou pelo contrário, de triunfar numa situação pode expressar-se por emoções diferentes, tal como a mesma emoção pode servir de expressão a sensações diferentes. Chorar de alegria ou rir de pavor demonstra-o bem" (2017, p. 185). A emoção, resultado de uma desorganização orgânica, torna visível e observável o afeto: a emoção toma, portanto, forma no afeto - surgindo este no ponto de conflito entre a experiência já tida e a experiência em vias de o ser. Daí a constatação de que "se os afetos passam pelo corpo não provêm dele. Vêm da atividade que liga o sujeito ao real" (idem, p. 186). É no contacto com o real que resiste que o afeto remata a emoção na e pela atividade e facilita a ancoragem dos sentimentos daí decorrentes na realidade social, fazendo assim destes últimos, tornando-os discutíveis entre pares, instrumentos possíveis de ultrapassagem dos conflitos encontrados na ação [8].

Françoise Parot (1996), constatando o fracasso institucional da psicologia histórica de Ignace Meyerson (1888-1983) para sublinhar a dificuldade do trabalho interdisciplinar, único garante do "saber plural", apela à modéstia. Do lado da história, Damien Boquet $\mathrm{e}$ Piroska Nagy (2016), revisitando a "história das emoções" interrogam-se se o programa de história da sensibilidade da qual Febvre estabelece as grandes linhas não é demasiado ambicioso para poder ser bem levado a cabo. Para lá destas constatações é talvez o momento de refletir na necessidade de obter os meios de abrir, do lado da psicologia, novos estaleiros para "cavar" as pistas existentes e abrir novas vias para facilitar e desenvolver a colaboração entre disciplinas, sem menosprezar a dificuldade de um tal trabalho. Esse é o sentido desta contribuição em que revisitamos uma página de história da psicologia para reinterrogar as ligações entre a psicologia e a história a partir do texto fundador de Lucien Febvre. Mau grado algumas aberturas (Bonnefond, 2019; Clot, 2021; Bonnemain \& Tomàs, 2021), o interesse em desenvolver o diálogo entre os psicólogos e os historiadores está ainda longe de se impor no campo da psicologia para compreender melhor o que realmente fazem mulheres e homens no trabalho. Desde logo os ergónomos e os psicólogos do trabalho têm um importante papel a desempenhar para esclarecer, na esteira de Lucien Febvre e de Henri Wallon, o interesse epistemológico duma colaboração entre psicólogos e historiadores. A psicologia devia tirar proveito desses debates.

\section{BIBLIOGRAFIA}

Aubert, S. (1996). Des connaissances incorporées. L'énonciation des règles de métier : les savoirfaire collectifs dans le ballet des peintres aéronautiques (DEA d'ergonomie). Conservatoire national des arts et métiers, Paris, France.

Bonnefond, J.-Y. (2019). Agir sur la qualité du travail. L'expérience de Renault Flins. Toulouse : Erès.

Bonnemain, A., \& Tomàs, J.-L. (2021, in press). Régénérer l'histoire des affects dans l'institution. In J. Martin, \& B. Prot (Dirs.), Émotions, affects et institutions. Dialogue entre historiens et psychologues. Toulouse : Octarès. 
Boquet, D., \& Nagy, P. (2016). Una storia diversa delle emozioni. Rivista Storica Italiana, 128(2), 481-520.

Bouffartigue, P., \& Vandewattyne, J. (2021). Facteurs en Europe. Le syndicalisme face à la libéralisation et aux mutations des activités postales : Belgique, Bulgarie, Espagne, France et Royaume-Uni. Toulouse : Octarès.

Braudel, F. (1986). L’identité de la France. Les hommes et les choses (T. 2). Paris : Flammarion.

Cahour, B., \& Lancry, A. (2011). Éditorial : Émotions et activités professionnelles et quotidiennes. Le Travail Humain, 74(2), 97-106. https://doi.org/10.3917/th.742.0097

Clot, Y. (2017). Postface : l'affect et sa signification. In L. Vygotski (1931/2017), Conscience, inconscient, émotions (pp. 153-204). Paris : La Dispute.

Clot, Y. (2021, in press). Psychologie, affectivité, histoire. In J. Martin, \& B. Prot (Dirs.), Émotions, affects et institutions. Dialogue entre historiens et psychologues. Toulouse : Éditions Octarès.

Curie, J., \& Dupuy, R. (1996). L'organisation du travail contre l'unité du travailleur. In Y. Clot (Dir.), Les histoires de la psychologie du travail. Approche pluridisciplinaire (pp. 141-156). Toulouse : Octarès.

Curie, J., \& Hajjar, V. (1987). Système des activités et niveaux de processus psycho-sociaux dans les changements personnels et sociaux. Psychologie et Éducation, 11(1-2), 47-56.

Febvre, L. (1938). Psychologie et histoire. In H. Wallon (Dir.), La vie mentale. L'Encyclopédie Française - Tome VIII (pp. 8'12-3-8'12-7). Paris : Larousse.

Febvre, L. (1941). La sensibilité et l'histoire: Comment reconstituer la vie affective d'autrefois? Annales D'histoire Sociale (1939-1941), 3(1/2), 5-20.

Fortino, S. (2015). La mise au travail des émotions. Travail émotionnel des conducteurs de train et émergences de nouvelles actions. Terrains/Théories, 2. https://doi.org/10.4000/teth.279

Le Goff, J. (1974/1986). Les mentalités. Une histoire ambigüe. In J. Le Goff, \& P. Nora (Dirs.), Faire de l'histoire. Vol. III Nouveaux objets (pp. 106-129). Paris : Gallimard.

Malrieu, Ph. (1963). La vie affective de l'enfant. Paris : Éditions du Scarabée (CEMEA).

Malrieu, Ph. (1981), Introduction. In Hommage à Henri Wallon pour le centenaire de sa naissance - Série A, Tome XIV (pp. 3-5). Travaux de l'Université de Toulouse-Le Mirail.

Ouvrier-Bonnaz, R., \& Prot, B. (2006). L'analyse de l'activité des chefs d'équipe : une ressource pour le recrutement et la formation. Étude réalisée pour la mission Recherche de La Poste. Document multigraphié. Paris : INETOP/CNAM.

Parot, F. (1996). Présentation. In Pour une psychologie historique. Écrits en hommage à Ignace Meyerson (pp. 1-5). Paris : PUF.

Poussin. N. (2014), Développement des sentiments au travail : dialogues sur l'efficacité et l'utilité chez les médecins du travail (Thèse de doctorat). Conservatoire national des arts et métiers, Paris, France.

Trempé, R. (1971). Les mineurs de Carmaux, 1848-1914. Paris : Les Éditions Ouvrières (Tome 1).

Wallon, H. (1938). Rapports affectifs : les émotions. In H. Wallon (Dir.), La vie mentale.

L’Encyclopédie Française - Tome VIII (pp. 8'24-1-8'24-7). Paris : Larousse. 


\section{NOTAS}

1. O projeto de uma enciclopédia foi iniciado por De Monzie, ministro da Educação nacional, em 1932, e a direção científica confiada ao historiador Lucien Febvre, um próximo do psicólogo Henri Wallon que coordenou o tomo VIII em que figura o texto comentado.

2. Texto que será comentado por Jérôme Martin no número de Laboreal de julho 2022, a partir da versão publicada em 1941 e republicada em Combats pour l'histoire (edição de 1992).

3. Para uma história do conceito de emoção em psicologia nos séc. XIX e XX (Ribot, Janet, Wallon e Malrieu), ver a tese de Nadine Poussin (2014).

4. As palavras em itálico nesta citação são da iniciativa do autor. Febvre retoma aqui a descrição de Wallon da constituição do processo através do qual se modela, no seio de uma coletividade, um sistema de emoções - Tomo VIII da Encyclopédie Française (ref. 8. 24-6).

5. A este respeito podemos referir-nos ao estudo que Sophie Aubert (1996) consagrou aos pintores da aeronáutica.

6. Um filme realizado em 1998, no decorrer de um estudo, pelo laboratório APTS-Recherche da Université de Provence, «Les compétences à la Poste: outils, stratégies, activités », do qual uma parte trata da competência do chefe de equipa no Centre de Distribution Courrier (CTC), permite ver em beleza esta coreografia.

7. Os de Fernand Braudel (1986) e os de Rolande Trempé (1971).

8. Ver também sobre a questão da emoção em ligação com o trabalho, o artigo de Cahour \& Lancry (2011) ou ainda, em sociologia, Fortino (2015).

\section{AUTORES}

\section{RÉGIS OUVRIER-BONNAZ}

Groupe de Recherches sur l'Histoire du Travail et de l'Orientation (GRESHTO); Centre d'Études sur le travail et le développement (CRTD); Centre National des Arts et Métiers (CNAM), INETOP, 41 rue Gay Lussac - 75005 Paris. regis.ouvrier-bonnaz@lecnam.net 